\title{
Copolymer Based on Polyglycerol-Acrylate-Lactate as Potential Water Viscosifier and Surfactant for Enhanced Oil Recovery
}

\author{
M. P. Amaya-Gómez, ${ }^{1}$ L. M. Sanabria-Rivas, ${ }^{1}$ A. M. Díaz-Lasprilla, ${ }^{1}$ C. Ardila-Suárez, ${ }^{1,2}$ \\ R. H. Castro-García, ${ }^{3}$ H. I. Quintero-Pérez, ${ }^{3}$ and G. E. Ramírez-Caballero ${ }^{1,2}$ \\ ${ }^{1}$ Grupo de Investigación en Polímeros, Colombia \\ ${ }^{2}$ Centro de Investigaciones en Catálisis (@CICATUIS), Parque Tecnológico de Guatiguará (PTG), km 2 vía El Refugio, \\ Universidad Industrial de Santander Piedecuesta (Santander), 681011, Colombia \\ ${ }^{3}$ Ecopetrol S.A.-Centro de Innovación y Tecnología (ICP), A.A. 4185. km. 7 vía Piedecuesta (Santander), Colombia
}

Correspondence should be addressed to G. E. Ramírez-Caballero; gusramca@uis.edu.co

Received 24 July 2020; Revised 16 September 2020; Accepted 30 September 2020; Published 3 November 2020

Academic Editor: Mehdi Salami-Kalajahi

Copyright (C) 2020 M. P. Amaya-Gómez et al. This is an open access article distributed under the Creative Commons Attribution License, which permits unrestricted use, distribution, and reproduction in any medium, provided the original work is properly cited.

\begin{abstract}
Polymer and surfactant flooding are widely applied processes in enhanced oil recovery (EOR) in which viscous polymers or surfactants aqueous solutions are introduced in oil reservoirs to rise the recovery of the remaining oil. In this regard, one of the challenges of EOR practices is the use of efficient but low-cost viscosifier and surfactant polymers. This work is aimed at synthesizing a polyglycerol derived from the biodegradable and nontoxic monomer, glycerol, and evaluating the effect of its copolymerization on rheological and interfacial properties, which were tested in water and brine for the former and in the water/oil system for the last properties. The copolymers were synthesized using a polyglycerol backbone, acrylic acid, lactic acid, and oleic acid. The chemical structure of copolymers was characterized by Fourier transform infrared spectroscopy (FT-IR), thermogravimetry (TG), and differential scanning calorimetry (DSC). The viscosity and the interfacial tension (IFT) of polymeric solutions were tested. Thus, the viscosity and surface performance of the prepared polymer solutions in distilled water and brine were analyzed according to the structure of the synthesized polymers. The results showed that the synthesized polymers modified water viscosity and surface tension between water and oil. The developed polymers could be candidates for applications in enhanced oil recovery and related applications.
\end{abstract}

\section{Introduction}

Polymer flooding is an enhanced oil recovery (EOR) technique that consists in the addition of high molecular weight polymers-water solutions into the reservoir. The goal is to decrease the water/oil mobility ratio by increasing the viscosity of the displacing water leading to the improvement of recovery efficiencies $[1,2]$. Partially hydrolyzed polyacrylamide (HPAM) is the most extensively used synthetic and water-soluble polymer for EOR applications in the world and Colombia [3]. Despite HPAM's favorable performance modifying water viscosity and its tolerance to shear forces during reservoir flooding, its performance is compromised by interactions with charged species in solution and by its sensibility to hydrocarbons and surfactants [4]. Additionally, the use of synthetic polymers in EOR leads to environmental issues since nonbiodegradable polymers remain retained in the reservoir [5]. Consequently, the current work focuses on the use of biopolymer-based EOR formulations.

The burden on the environment of bio-based polymers is lower compared to petroleum-based polymers. In this context, glycerol, a bio-based monomer, arises as an interesting candidate for sustainable polymer production due to its structure, biocompatibility, and biodegradability [6]. The amount of commercialized biofuels had significantly increased in the last decade as a response to the commitments made by the G20 in 2009 and signed for more than 50 countries for the progressive elimination of subsidies for fossil fuels [7]. In the specific case of biodiesel, its production is expected to be approximately 40 billion liters in 


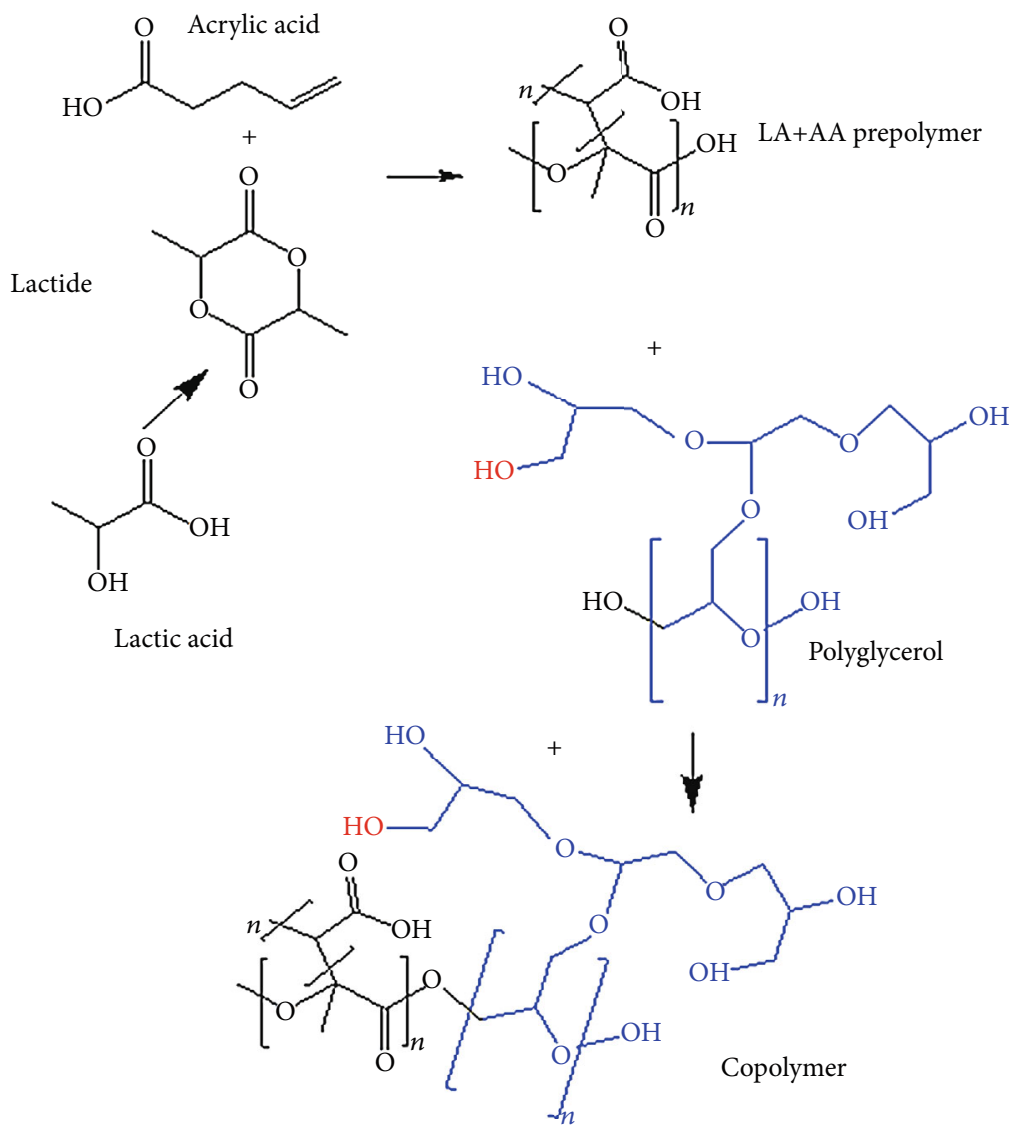

Scheme 1: Schematic representation of the copolymer COP $30 \mathrm{w} / \mathrm{w} \% \mathrm{LA}+\mathrm{AA}$ formation from lactic and acrylic acid prepolymerization and the subsequent polymerization with the polyglycerol matrix.

2027, propitiated by favorable policies in developing countries, i.e., Indonesia, Argentina, and Brazil [8]. Glycerol, as a coproduct of the transesterification of triglycerides, should be used as the precursor of high-added value products due to its overproduction that exceeds the demand of this chemical [9].

High value-added products from glycerol are polymers [10]. These include polyglycerol, which is formed by an inert polyether backbone [11,12], and an abundant number of highly reactive and exposed hydroxyl groups that allow polyglycerol modification for a wide variety of derivative compounds. Salehpour and Dubé [13] evaluated the use of sulfuric acid as homogeneous catalysts for glycerol polymerization using reduced pressures. They synthesized polyglycerols of relatively high molecular weights. Industrially, polyglycerol is produced from the glycidol by a ringopening polymerization reaction leading to polymers with narrow molecular weight distribution that goes from 1000 to $30000 \mathrm{~g} / \mathrm{mol}$ [14-16]. However, high molecular weight polyglycerols from glycerol could replace the polymers from glycidol, a toxic monomer [17], opening new applications for this polymer. In this regard, the possible use of polyglycerolbased polymers as water viscosifiers and surfactants for EOR could be an interesting option to afford challenges in EOR related to thermal stability, resistance to multivalent salts, and polymer adsorption on rock surfaces [18-20].
Previous research has studied the effect of synthesis conditions on glycerol polymerization, using sulfuric acid as the catalyst [21]. The obtained polyglycerols exhibited higher molecular weights compared to polymers synthesized using basic catalysts; however, these molecular weights are still low for applications such as EOR flooding. The copolymerization then emerges as an alternative to increase the molecular weight of the base polyglycerol. Indeed, the polyglycerol versatility due to its multiple hydroxyl groups leads feasible modifications that, in addition to increasing the molecular weight of the initial polymers, could add further functional groups.

Previous works have reported the copolymerization from polyglycerol as an approach to increase molecular weight. Wurm et al. [22] synthesized copolymers from polyglycerol and poly(ethylene oxide). Through the controlled addition of the copolymer, they were able to increase the initial molecular weight more than three times. On the other hand, Chen et al. [23] prepare a copolymer with poly(2-hydroxyethyl methacrylate) arms within a polyglycerol backbone. The final copolymer exhibited molecular weights around $1.4 \times 10^{5} \mathrm{Da}$. In this work, polyglycerols are copolymerized with lactic acid and acrylic acid prepolymers.

Lactic acid is a relevant organic acid, which is also a key platform molecule that can be produced from agricultural residues and can be used as a monomer for the poly(lactic 
TABLE 1: Nomenclature of the synthesized polymers.

\begin{tabular}{lc}
\hline Copolymer & Nomenclature \\
\hline Polyglycerol & PG \\
Polyglycerol and lactic acid prepolymer & COP 30 w/w $\%$ LA \\
Polyglycerol and acrylic acid prepolymer & COP 30 w/w\% AA \\
Polyglycerol and lactic+acrylic acid prepolymer & COP 30 w/w $\%$ LA+AA \\
Polyglycerol, lactic+acrylic acid prepolymer, and oleic acid & COP 30 w/w\% LA+AA-5\% OA \\
\hline
\end{tabular}

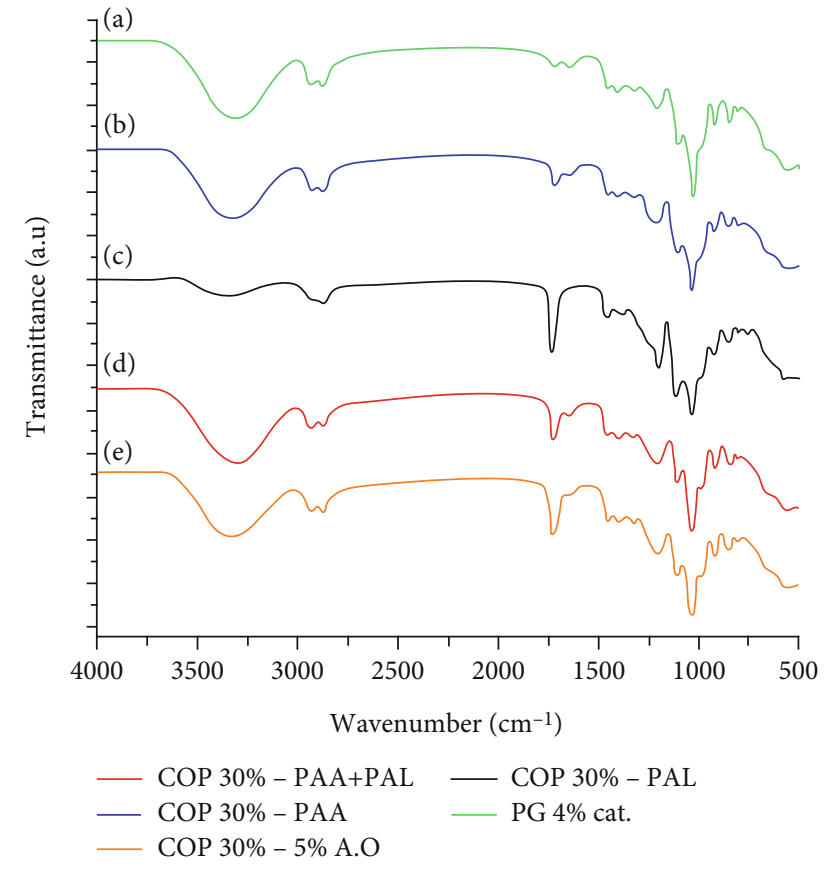

FIGURE 1: IR spectra of synthesized polyglycerol and copolymers.

acid) (PLA) synthesis. These polymeric products exhibit a high potential for a wide range of applications [24]. Several authors had reported the polymerization of poly(lactic acid) with polyglycerol (from glycidol) $[25,26]$. In these works, the final polymers displayed multiarms of poly(lactic acid) and a polyglycerol-based backbone with different degrees of hydroxyl functionalities. On the other hand, although acrylic acid is usually synthesized from propylene [27], it can also be from a renewable source, glycerol $[28,29]$. Furthermore, different authors reported the synthesis of copolymers based on acrylic acid and glycerol [30] and also polyglycerol [31]. The final polymers are polyelectrolytes with $\mathrm{pH}$ response.

The copolymerization can be accomplished through microwave irradiation, under mild conditions and short times [32, 33]. Microwave-assisted polymerization had been reported for the synthesis of copolymers using poly(lactic acid) (PLA) [34] or poly(acrylic acid) (PAA) [35] and polysaccharides, in which the terminal hydroxyl groups of the biopolymers are used for the modifications with the mentioned copolymers. Nevertheless, these copolymerization reactions could be successively scaled up in future works with the possibility of using different heat sources.
This work is aimed at developing a bio-based and lowcost polymer from glycerol, acrylic acid, lactic acid, and oleic acid that modifies water viscosity and interfacial tension between water and oil. The developed polymer was synthesized by the copolymerization of polyglycerol, polyacrylic acid, and polylactic acid in an initial stage. Furthermore, we esterified the copolymer using oleic acid as the esterification agent to provide surfactant features. The chemical structure and thermal properties of final polymers were characterized. Additionally, viscosity and interfacial tension of the polymeric solution were tested. This work is the initial step in the development of bio-based and low-cost polymers from polyglycerol for enhanced oil recovery. Further studies are necessary to determine the complete polymer viability in enhanced oil recovery, such as rock-fluid compatibility and mechanical, chemical, and biological degradation tests.

\section{Experimental Section}

2.1. Materials. Glycerol (98\%) was obtained from Laboratorios León S.A and sulfuric acid (95\%) from Merck. The glycerol was roto-evaporated to remove water and impurities. Oleic acid was obtained from Laboratorios León S.A., acrylic acid from Andercol, lactic acid from Carlo Erba, cesium carbonate (99\%) from Sigma-Aldrich, and potassium peroxodisulfate from Merck. Acetic anhydride (98\%) and pyridine (99\%) were obtained from PanReac and phenolphthalein indicator and sodium hydroxide (99\%) from Merck.

2.2. Polymerization Processes. Preliminary glycerol polymerization tests were performed according to previous works [21, 36]. Accordingly, the initial glycerol amount and sulfuric acid $(1 \% \mathrm{w} / \mathrm{w})$ were stirred at $500 \mathrm{rpm}$ for $5 \mathrm{~min}$ at room temperature. Then, the mixture was put in the microwave reactor (Discover Labmate Reactor, CEM Corporation), varying reaction time until finding the gel point of glycerol polymerization. The CEM microwave system (operated at $2.45 \mathrm{GHz}$ and 100 watts) counts with a $100 \mathrm{~mL}$ reactor coupled to a nitrogen inlet, catalyst feeding, and distillation trap to remove water from the reaction mixture continuously. A vacuum pump was attached to the reactor through the condenser.

2.3. Lactic Acid Prepolymerization. For the prepolymerization of lactic acid, the same CEM system mentioned above was used without the use of a vacuum. Thus, $25 \mathrm{~g}$ of lactic acid and cesium carbonate $(0.5 \% \mathrm{w} / \mathrm{w})$, the catalyst, was added to the reactor, and the reaction proceeds for $20 \mathrm{~min}$ at $140^{\circ} \mathrm{C}$, according to Ghadamyari et al. [37]. 
TABLE 2: The molecular weight of synthesized polymers.

\begin{tabular}{lccc}
\hline Polymer & Polyglycerol & $\begin{array}{c}\text { PRE } \\
\text { AA+LA }\end{array}$ & $\begin{array}{c}\text { COP 30\% } \\
\text { AA+LA }\end{array}$ \\
\hline $\begin{array}{l}\text { Molecular weight }\left(M_{w}\right. \\
\text { ) (Da) }\end{array}$ & 209805 & 725270 & 592876 \\
$\begin{array}{l}\text { Molecular weight }\left(M_{n}\right), \\
(\mathrm{Da})\end{array}$ & 8239 & 30473 & 24600 \\
\hline
\end{tabular}

TABLE 3: Hydroxyl values of synthesized materials according to ASTM D4274-16 standard.

\begin{tabular}{lc}
\hline Polymer & Hydroxyl value $(\mathrm{mg} \mathrm{KOH} / \mathrm{g})$ \\
\hline Polyglycerol & $506.7 \pm 23$ \\
COP 30 w/w\% LA & $222.4 \pm 29.5$ \\
\hline
\end{tabular}

2.4. Lactic and Acrylic Acids Prepolymerization. This prepolymerization was carried out in a $150 \mathrm{~mL}$ glass two-neck round bottom flask. A condenser is connected to one of the necks, and water reflux was guaranteed. The temperature was set at $80^{\circ} \mathrm{C}$ throughout an oil bath. For the acrylic acid prepolymerization, we followed the protocol established by Fernandes et al. [30] with some modifications. Two different solutions were prepared. $10 \mathrm{~g}$ of acrylic acid was added to two $21.42 \mathrm{~g}$ of distilled water, solution A. In solution B, $0.4712 \mathrm{~g}$ of KPS were added to $15.24 \mathrm{~g}$ of distilled water. Solution $\mathrm{A}$ is added to the reactor, and then solution B is added. The prepolymerization proceeds for $7 \mathrm{~min}$. Then, the prepolymer was dried at $50^{\circ} \mathrm{C}$ for $24 \mathrm{~h}$.

In the same way, the prepolymerization of both acrylic and lactic acids was carried out by using the same two solutions A and B of prepolymerization of acrylic acid. Additionally, $10 \mathrm{~g}$ of lactic acid prepolymer was added. The reaction proceeded for $28 \mathrm{~min}$, and the reaction mixture was dried in the oven for $24 \mathrm{~h}$ at $55^{\circ} \mathrm{C}$. The final prepolymers were named as PRE LA, PRE AA, and PRE LA+AA for lactic acid prepolymer, acrylic acid prepolymer, and lactic acid+acrylic acid prepolymer, respectively.

2.5. Polyglycerol Synthesis and Copolymerization. The polyglycerol synthesis was carried out using the CEM microwave system. At first, the initial amount of glycerol was added into the glass reactor of the CEM microwave system with $1 \mathrm{w} / \mathrm{w} \%$ sulfuric acid. The solution was stirred at $500 \mathrm{rpm}$ for $14 \mathrm{~min}$. During the reaction time, a total of $4 \% \mathrm{w} / \mathrm{w}$ sulfuric acid addition was divided in 4 additions divided at equal quantities $(1 \% \mathrm{w} / \mathrm{w})$ and time. Then, the final polymer is weighted. Afterward, $30 \mathrm{w} / \mathrm{w} \%$ of prepolymer (acrylic, lactic, or the combination of two acids) was added to the freshly synthesized polyglycerol.

Additionally, $2 \mathrm{w} / \mathrm{w} \%$ of KPS was added related to the total weight of the reaction mass. The mixture was stirred for $5 \mathrm{~min}$ and was put in the CEM reaction system at the same temperature of polyglycerol synthesis until reached the gel point. A schematic representation of the copolymerization process is presented in Scheme 1. The glycerol polymerization is performed before the copolymerization in order to guarantee the growth of polyglycerol chains, before adding other functionalities.

2.6. Copolymer Esterification. For the subsequent esterification process, the copolymerization between polyglycerol and PRE AA+LA time is reduced to $2 \mathrm{~min}$, after which $5 \%$ of oleic acid is added. The esterified copolymer using $5 \%$ of oleic acid is named COP $30 \%-5 \% \mathrm{AO}$. The reaction mixture is stirred for $5 \mathrm{~min}$ and continued the reaction at the CEM system until COP 30\%-5\% AO reached the gel point. The synthesized polymers were named as listed in Table 1.

\subsection{Preparation of Polymer Solutions for EOR Application.}

For testing the synthesized polymers as viscosifier agents, solutions at $10000 \mathrm{ppm}$ of the polyglycerol copolymer were prepared. For that, the solutions were heating at $60^{\circ} \mathrm{C}$ for $2 \mathrm{~h}$ and stirred at $600 \mathrm{rpm}$. Afterward, the solutions were maintained under agitation using a Heidolph RZR-2021 for $24 \mathrm{~h}$. The solutions were prepared using distilled water and brine of $700,900,1400,1900$, and $3900 \mathrm{ppm}$. The brine was prepared using the $\mathrm{NaCl}, \mathrm{KCl}, \mathrm{MgCl}_{2} \cdot 6 \mathrm{H}_{2} \mathrm{O}$, and $\mathrm{CaCl}_{2} \cdot 2 \mathrm{H}_{2} \mathrm{O}$ in the following ratios, respectively: $2.97,0.13$, 0.24 , and $0.58 \mathrm{~g} / \mathrm{L} .1 .0 \mathrm{~N}$ sodium hydroxide solution was used to neutralize the polymer solutions.

2.8. Polymer Characterization. The infrared analysis was performed using a Thermo Scientific (iS50 ATR) spectrometer. The molecular weight of the synthesized polymers was analyzed through the SEC technique using a TSKgel G3000 PWxl column with separation range from 100 to $60.000 \mathrm{Da}$. Deionized water as the mobile phase and polyethylene glycol standards were used. The following conditions were set: $0.5 \mathrm{~mL} / \mathrm{min}$ flux, $40^{\circ} \mathrm{C}$, and $20 \mu \mathrm{L}$ of volume injection. Differential scanning calorimetry (DSC) test was carried out to analyze the glass transition temperature, $\mathrm{Tg}$, of the synthesized polymers. A Discovery DSC, TA instrument equipment was used. The following procedure was set: a first heating from -80 to $140^{\circ} \mathrm{C}$ at $5^{\circ} \mathrm{C} / \mathrm{min}$, followed by cooling to $-80^{\circ} \mathrm{C}$ at $10^{\circ} \mathrm{C} / \mathrm{min}$ and final heating to $400^{\circ} \mathrm{C}$ at $5^{\circ} \mathrm{C} / \mathrm{min}$ under $50 \mathrm{~mL} / \mathrm{min}$ nitrogen atmosphere. Thermogravimetric analysis was performed with a Thermogravimetric Analyzer TGA 5500, TA instruments. A temperature range from 30 to $700^{\circ} \mathrm{C}$ at a heating rate of $5^{\circ} \mathrm{C} / \mathrm{min}$ was used with a nitrogen purge gas system $(25 \mathrm{~mL} / \mathrm{min})$. The hydroxyl number was calculated according to the ASTM D4274-16 method. The viscosity was measured using a Brookfield viscosimeter at 30,50 , and $80^{\circ} \mathrm{C}$ with a shear rate of $7.338 \mathrm{~s}^{-1}$. Finally, spinning drop measurements were tested using a spinning drop M6500 tensiometer with a capillary diameter of $2 \mathrm{~mm}$. A Colombian field oil was used as a less dense phase, and a polymer solution was used as a more dense phase at $60^{\circ} \mathrm{C}$.

\section{Results and Discussion}

3.1. Infrared Spectroscopy. Infrared spectroscopy analysis was performed for the three synthesized prepolymers: PRE LA, PRE AA, and PRE AA+LA (supporting information (available here)), polyglycerol, and the copolymers at $30 \% \mathrm{w} / \mathrm{w}$ of each of the synthesized prepolymers (COP $30 \mathrm{w} / \mathrm{w} \% \mathrm{LA}$, COP $30 \mathrm{w} / \mathrm{w} \% \mathrm{AA}$, and COP $30 \mathrm{w} / \mathrm{w} \% \mathrm{LA}+\mathrm{AA})$. 


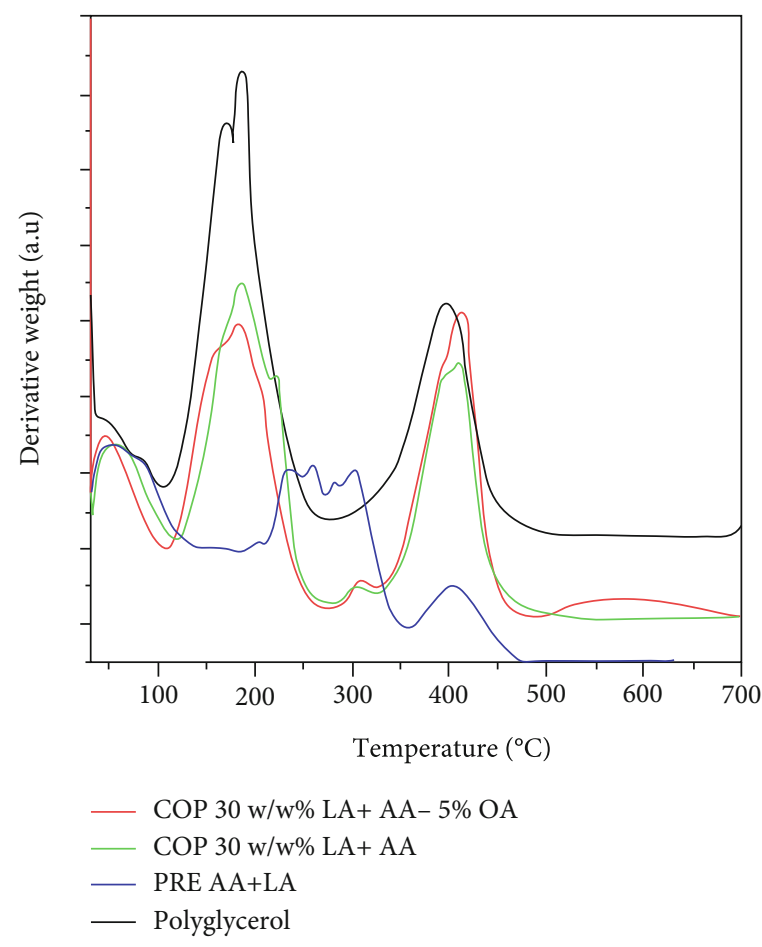

(a)

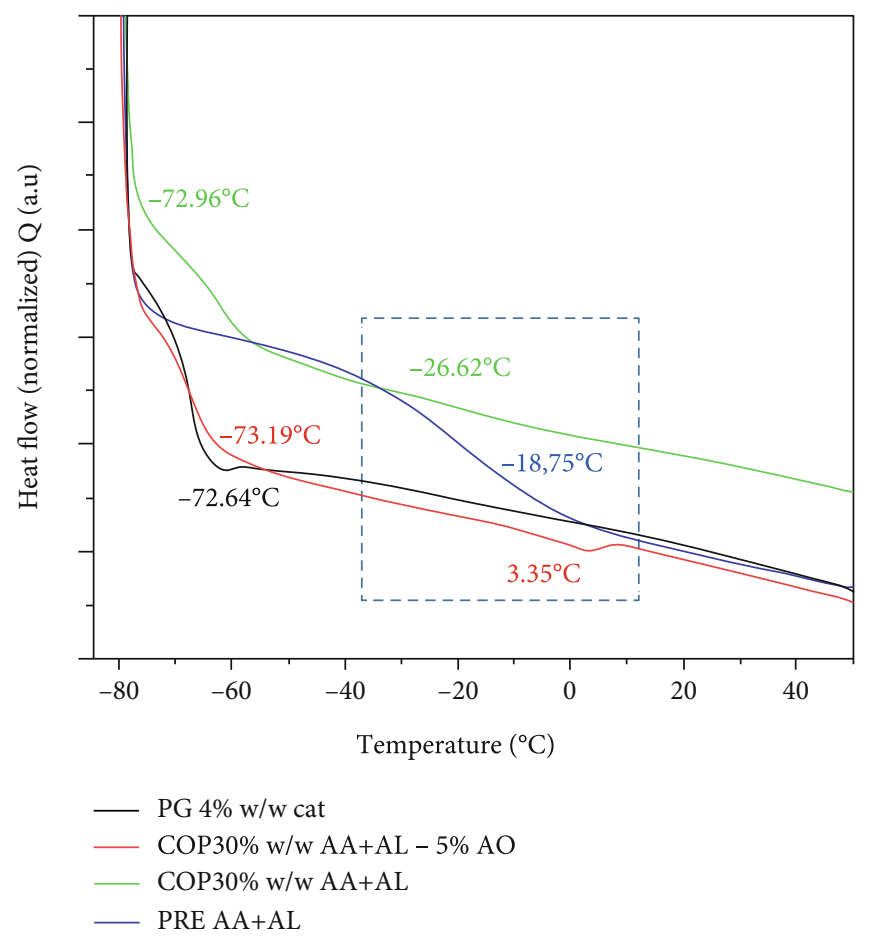

(b)

FIGURE 2: (a) Derivative weight and (b) DCS thermograms of synthesized materials.

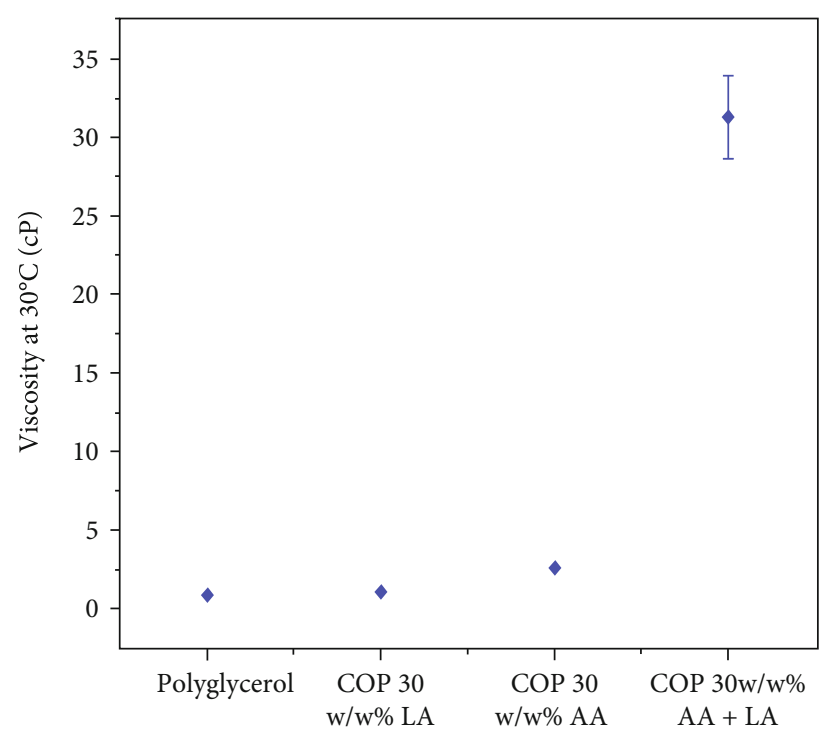

Polymer solution at $10.000 \mathrm{ppm}$

Figure 3: The viscosity of polymer solutions of $10.000 \mathrm{ppm}$ in distilled water at $30^{\circ} \mathrm{C}$.

Figure 1(a) shows the infrared spectra of synthesized polyglycerol, which is in agreement with our previous reports $[21,36]$. Accordingly, polyglycerol exhibits its characteristic $\mathrm{O}-\mathrm{H}$ band from 3600 to $3050 \mathrm{~cm}^{-1}$. The $\mathrm{C}-\mathrm{H}$ stretching is observed from 3000 to $2800 \mathrm{~cm}^{-1}$. Peaks in the 1750 $1700 \mathrm{~cm}^{-1}$ are related to the formation of acrolein, a reaction subproduct [13]. The peaks in the range from 1150-

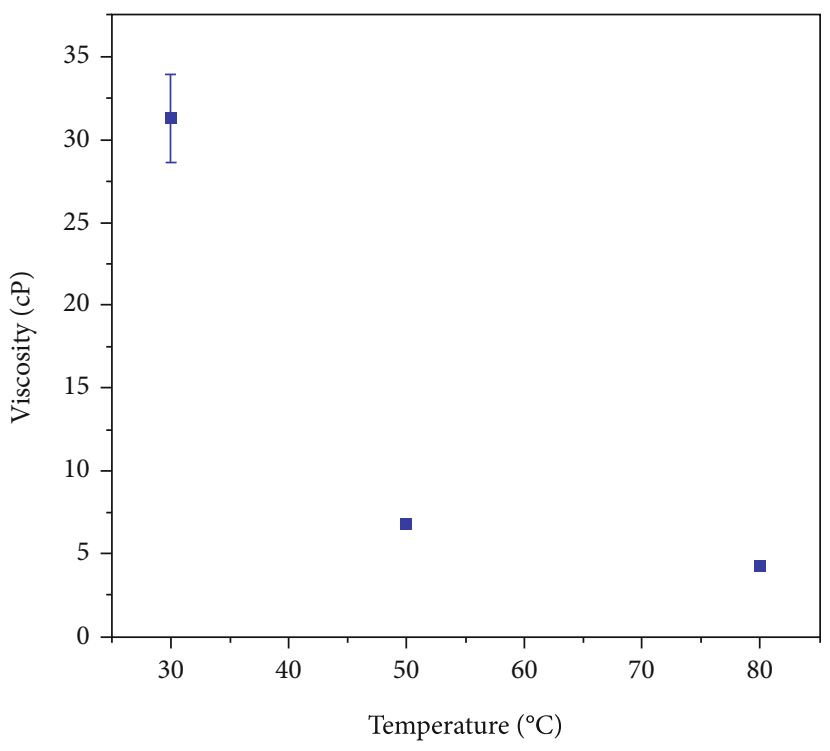

FIgURE 4: The viscosity of COP $30 \mathrm{w} / \mathrm{w} \%$ AA+LA solution of $10.000 \mathrm{ppm}$ in distilled water at different temperatures.

$1000 \mathrm{~cm}^{-1}$ are associated with the $\mathrm{C}-\mathrm{O}$ stretching from ether groups of polyglycerol backbone [38].

Figure 1(b) shows the COP $30 \mathrm{w} / \mathrm{w} \%$ AA spectra. Besides the characteristic peaks from polyglycerol, it is observed a defined peak at $1718 \mathrm{~cm}^{-1}$ related to the $\mathrm{C}=\mathrm{O}$ stretching of carbonyl groups of the PRE AA. Furthermore, at 1456 and $1407 \mathrm{~cm}^{-1}$ are found the asymmetric and symmetric COOstretching, respectively, of the carboxylate anion [39]. 
TABLE 4: Viscosity measurements of COP $30 \mathrm{w} / \mathrm{w} \%$ AA+LA copolymer by using different brine concentrations.

\begin{tabular}{lccc}
\hline $\begin{array}{l}\text { Brine } \\
\text { concentration } \\
(\mathrm{ppm})\end{array}$ & $\begin{array}{c}\text { Viscosity at } \\
30{ }^{\circ} \mathrm{C}(\mathrm{cP})\end{array}$ & $\begin{array}{c}\text { Brine } \\
\text { concentration } \\
(\mathrm{ppm})\end{array}$ & $\begin{array}{c}\text { Viscosity at } \\
30{ }^{\circ} \mathrm{C}(\mathrm{cP})\end{array}$ \\
\hline 400 & $2.67 \pm 0.73$ & 1900 & $0.65 \pm 0.06$ \\
900 & $16.22 \pm 1.13$ & 3900 & $2.92 \pm 0.16$ \\
1400 & $2.07 \pm 0.18$ & & \\
\hline
\end{tabular}

Figure 1(c) showed the COP $30 \mathrm{w} / \mathrm{w} \%$ LA copolymer. Similarly to the copolymer mentioned above, it is observed the $\mathrm{C}=\mathrm{O}$ stretching at $1750 \mathrm{~cm}^{-1}$ indicating the incorporation of PRE LA segments to the polyglycerol backbone [40]. Accordingly, the incorporation of these individual prepolymers in the polyglycerol backbone is also observed for the COP $30 \mathrm{w} / \mathrm{w} \% \mathrm{AA}+\mathrm{LA}$ in which is evidenced by the incorporation of the mentioned prepolymers to the polyglycerol backbone (see Figure 1(d)) [41]. Finally, Figure 1(e) shows the COP 30\%-5\% AO spectra in which are observed nearly the same bands of Figure 1(d). However, the proportion of oleic acid ( $5 \%$ related to polyglycerol) is low. Then, the esterification of the copolymer could be reflected just in a slight increase of $\mathrm{C}=\mathrm{O}$ stretching at $1750 \mathrm{~cm}^{-1}$ that could be related to the oleic acid addition to the copolymer backbone through esterification reactions.

3.2. Polymers Molecular Weight. The molecular weight of the developed bio-based polymers is displayed in Table 2 . Accordingly, the polymer with the more considerable molecular weight is the PRE AA-LA, followed by the copolymer using this same prepolymer, COP $30 \mathrm{w} / \mathrm{w} \% \mathrm{AA}+\mathrm{LA}$, and ending with polyglycerol. These results agree with the reported by Wurm et al. [22]. The authors showed that the synthesized copolymers increase more than three times their molecular weight compared to the base polymer, a combination of poly(ethylene oxide) and hyperbranched polyglycerol. In our case, the COP $30 \mathrm{w} / \mathrm{w} \% \mathrm{AA}+\mathrm{LA}$ increased 2.83 times its weight compared to the base polyglycerol. Furthermore, the molecular weight of prepolymer PRE AA-LA exhibited the same order of magnitude than the similarly synthesized polyacrylic acid copolymers previously reported [30]. As shown in Table 2, the polyglycerol and its derivative copolymers displayed broad molecular weight distributions related to the glycerols' step-growth polymerization process [11]. Furthermore, the highly polydisperse polymers reported herein agree with previous reports related to the glycerol step-growth polymerization towards the obtainment of polyglycerols of relatively high molecular weights $[13,38]$. The variations on molecular weight are also evidenced in the changes in the hydroxyl number of the materials (ASTM D4274-16). Polyglycerol and COP $30 \mathrm{w} / \mathrm{w} \%$ LA were the samples that could be diluted in the acetylating solution and tested. The obtained values after the acidity correction are shown in Table 3. According to the results, it is evident that the hydroxyl groups consume given by the etherification reaction and the subsequent copolymerization. These values are significantly lower than the glycerol hydroxyl number (1800 mg KOH/g) [42].

3.3. Thermal Analysis. The derivative weight as a function of the temperature of the synthesized PRE AA+LA, COP 30 w/w $\%$ AA+LA-5\% AO, COP $30 \mathrm{w} / \mathrm{w} \% \mathrm{AA}+\mathrm{LA}$, and polyglycerol samples are disclosed in Figure 2(a). All samples showed an initial weight loss related to the humidity and volatile materials. The second group of derivative weight loss peaks centered around $150^{\circ} \mathrm{C}$ is exhibited by polyglycerol and its derivative copolymers (COP $30 \mathrm{w} / \mathrm{w} \% \mathrm{AA}+\mathrm{LA}$ and COP $30 \mathrm{w} / \mathrm{w} \% \mathrm{AA}+\mathrm{LA}-5 \% \mathrm{AO}$ ), which is shifted to around $280^{\circ} \mathrm{C}$ for the PRE AA+LA prepolymer. These weight losses could be related to the unreacted monomers' removal. The COP $30 \mathrm{w} / \mathrm{w} \% \mathrm{AA}+\mathrm{LA}$ and COP $30 \mathrm{w} / \mathrm{w} \% \mathrm{AA}+\mathrm{LA}-5 \%$ AO copolymers displayed a small peak centered around $300^{\circ} \mathrm{C}$, which is not presented in the polyglycerol sample. This weight loss could be assigned to the incorporation of the PRE AA+LA into the polyglycerol backbone. Finally, around $350^{\circ} \mathrm{C}$ starts the decomposition step of materials. According to these results, the synthesized polymers do not decompose in the temperature range used for enhanced oil recovery applications.

The glass transition temperature, $\mathrm{Tg}$, of synthesized materials, polyglycerol, PRE AA+LA, COP $30 \mathrm{w} / \mathrm{w} \%$ $\mathrm{AA}+\mathrm{LA}$, and the esterified polymer COP $30 \mathrm{w} / \mathrm{w} \%$ $\mathrm{AA}+\mathrm{LA}-5 \% \mathrm{AO}$, are shown in Figure 2(b). The presented thermograms corresponded to the final heating run (after humidity removal). The glass transition could vary depending on the molecule's polymerization degree and branching degree [42]. Accordingly, it seems that the polyglycerolbased copolymers exhibited two different glass transition temperatures that could be related to the different chain segments $[43,44]$, contrary to the polyglycerol and PRE AA, which displayed a single glass transition temperature. Therefore, the glass transition temperature related to the polyglycerol segment of the polyglycerol-based materials increased according to the following trend: $-73.19^{\circ} \mathrm{C},-72.96^{\circ} \mathrm{C}$, and $-72.64^{\circ} \mathrm{C}$ for COP $30 \mathrm{w} / \mathrm{w} \% \mathrm{AA}+\mathrm{LA}-5 \%$ AO, COP 30 $\mathrm{w} / \mathrm{w} \% \mathrm{AA}+\mathrm{LA}$, and polyglycerol, respectively. A second glass transition is observed at $-26.62^{\circ} \mathrm{C}$ and $3.35^{\circ} \mathrm{C}$ for the COP 30 $\mathrm{w} / \mathrm{w} \% \mathrm{AA}+\mathrm{LA}$ and COP $30 \mathrm{w} / \mathrm{w} \% \mathrm{AA}+\mathrm{LA}-5 \% \mathrm{AO}$, respectively. This second glass transition could be related to PRE AA+LA and oleic acid segments' subsequent addition to the initial polyglycerol material.

3.4. Viscosity Measurement. The viscosity measurements were performed to $10000 \mathrm{ppm}$ of synthesized polyglycerol and copolymers. According to Figure 3, it was found that after copolymerization, there is an increase in the polymer solution viscosity. This growth is more significant using COP $30 \mathrm{w} / \mathrm{w} \%$ AA+LA copolymer with an average viscosity of $31.3 \mathrm{cP}$ at $30^{\circ} \mathrm{C}$. These results are in agreement with the reported by Fernandes et al. [30] in which the final copolymers obtain higher viscosities compared to the polyglycerol. We selected the COP $30 \mathrm{w} / \mathrm{w} \%$ AA+LA copolymer for further measurements at different temperatures. Figure 4 shows that an increase of temperature from $30^{\circ} \mathrm{C}$ to $50^{\circ} \mathrm{C}$ and $80^{\circ} \mathrm{C}$ decreases polymer solution viscosity by 78.25 and $86.55 \%$, 


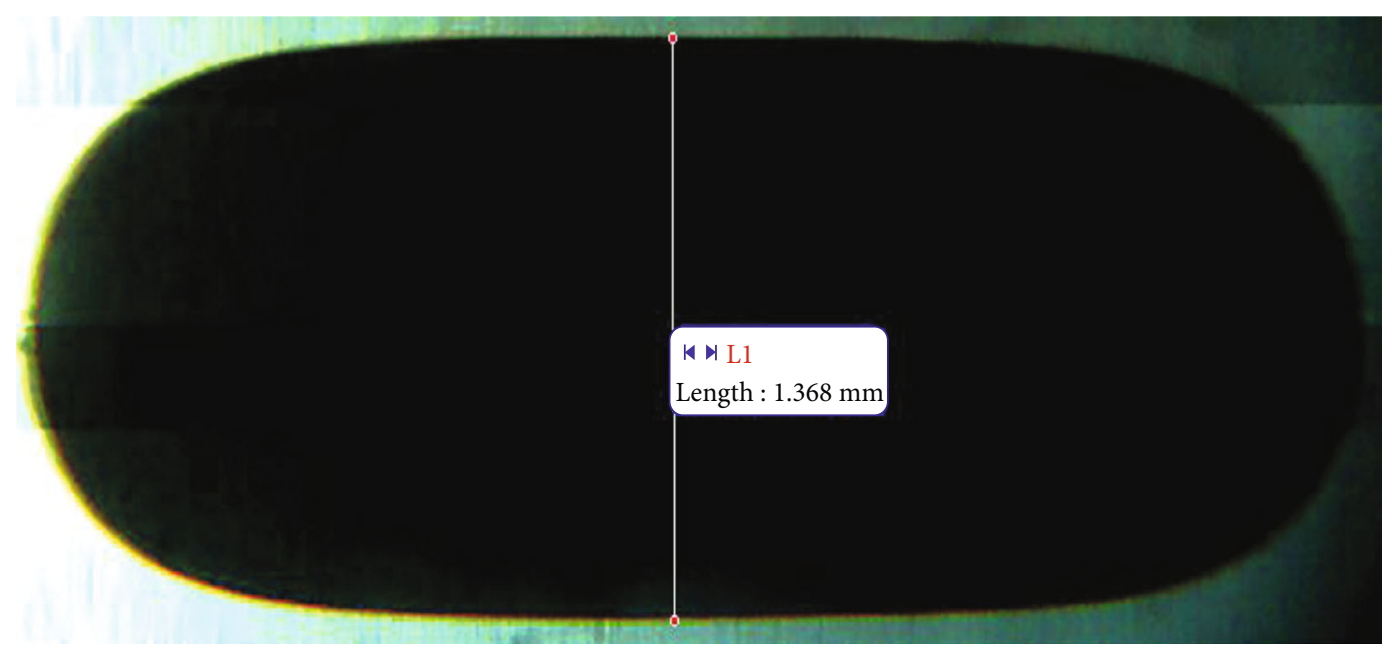

FIGURE 5: Crude oil drop deformation due to the decrease of interfacial tension between it and $5.000 \mathrm{ppm} \mathrm{NaCl}$ water phase using the COP 30 $\mathrm{w} / \mathrm{w} \% \mathrm{AA}+\mathrm{LA}-5 \% \mathrm{AO}$ at $10.000 \mathrm{ppm}$.

TABLE 5: Interfacial tension of COP $30 \mathrm{w} / \mathrm{w} \% \mathrm{AA}+\mathrm{LA}-5 \% \mathrm{AO}$ in $5.000 \mathrm{ppm} \mathrm{NaCl}$ solution.

\begin{tabular}{lcccccc}
\hline Solution & $\begin{array}{c}\text { Weight } \\
(\mathrm{g})\end{array}$ & $\begin{array}{c}\text { Volume } \\
\left(\mathrm{cm}^{3}\right)\end{array}$ & $\begin{array}{c}\text { Solution density } \\
\left(\mathrm{g} / \mathrm{cm}^{3}\right)\end{array}$ & $\begin{array}{c}\text { Agitation rate } \\
(\mathrm{rpm})\end{array}$ & $\begin{array}{c}\text { Diameter } \\
(\mathrm{mm})\end{array}$ & $\begin{array}{c}\text { Interfacial tension } \\
(\mathrm{mN} / \mathrm{m})\end{array}$ \\
\hline COP $30 \mathrm{w} / \mathrm{w} \% \mathrm{AA}+\mathrm{LA}-5 \% \mathrm{AO}$ & & & & & & \\
$10.000 \mathrm{ppm}$ & & & & & \\
$5.000 \mathrm{ppm} \mathrm{NaCl}$ & 5,0212 & 5 & 1,0042 & 7744 & 1,368 & 2.5256 \\
\hline
\end{tabular}

respectively. High temperatures could change copolymer chain conformation leading to a considerable reduction of its viscosity [45].

The COP $30 \mathrm{w} / \mathrm{w} \%$ AA+LA copolymer was further tested in viscosity measurements by using different brine concentrations. The results are shown in Table 4 . The viscosity measurements do not follow a trend related to brine concentration. The higher viscosities are achieved using 900 ppm of brine with $16.22 \mathrm{cP}$. Different authors had been studied the effect of different salts in the viscosity and found that it depends on the salt cation. Divalent cations $\left(\mathrm{Ca}^{+2}\right.$ and $\mathrm{Mg}^{+2}$ ) have a significant high effect on the decrease of solution viscosity than the monovalent cations $\left(\mathrm{Na}^{+}\right)$. Lopes et al. [46] found that the salts with more effect on the viscosity decrease of HPAM solutions are $\mathrm{NaCl}, \mathrm{CaCl}_{2}, \mathrm{KCl}, \mathrm{MgCl}_{2}$, and $\mathrm{SrCl}_{2}$. From these five salts, four were used in this work for the brine composition. Thus, it is expected the same effect of COO- groups of copolymers than the one showed on HPAM in which the acrylate moieties are strongly associated with cations $[47,48]$. Lastly, the esterified polymer was also tested in viscosity measurements. From the esterified polymers, only the esterified at 5\% with oleic acid (COP 30 w/w\% AA+LA-5\% AO) was effectively dissolved in distilled water. It was not possible to dissolve the esterified polymer with $10 \%$ of oleic acid, probably caused by crosslinking reactions between copolymer and the oleic acid [36, 49]. The resulted measurements of esterified samples showed that after the addition of oleic acid, the viscosity decrease to $1 \mathrm{cP}$.

3.5. Spinning Drop. The interfacial tension was calculated according to equation (1), where $\gamma$ is the interfacial tension
$(\mathrm{mN} / \mathrm{m}), \Delta \rho$ is the density difference of the two phases $\left(\mathrm{g} / \mathrm{cm}^{3}\right), D$ is the drop diameter $(\mathrm{mm})$, and $\theta$ is the rotation rate (rpm). Crude oil was used as the oily phase with a density of $0.89 \mathrm{~g} / \mathrm{cm}^{3}$. Figure 5 displayed the deformation of the oil drop of the 10000 ppm COP 30 w/w\% AA+LA-5\% AO solution in $5000 \mathrm{ppm} \mathrm{NaCl}$, and Table 5 shows the experimental data used in equation (1). It seems that this esterified polymer can down the interfacial tension to $2.5256 \mathrm{mN} / \mathrm{m}$, and this result is comparable, for example, with the results obtained using the bio-based sodium methyl ester sulfonate, which reached a decrease in interfacial tension until a value of $3.92 \mathrm{mN} / \mathrm{m}$ [50].

$$
\gamma=1.44 * 10^{-7} * \Delta \rho * D^{3} * \theta^{2}
$$

\section{Conclusions}

It was developed polyglycerol-based copolymers synthesized in sequential steps for the obtainment of viscosifying and surfactant polymers. The copolymers were synthesized first with the prepolymerization of lactic and acetic acid and the subsequent copolymerization with polyglycerol. Further, esterification of this polymer with oleic acid led to the obtainment of a surfactant. Their performance was investigated by rheological and interfacial analysis at different temperatures and polymer concentrations. After the copolymerization, the resulted polymer increases 2.83 times its molecular weight compared to the initial polyglycerol. This molecular weight increment led to a significant increase of the viscosifying capacity from 1 to $31.3 \mathrm{cP}$ of the $10.000 \mathrm{ppm}$ polymer 
solution at $30^{\circ} \mathrm{C}$. However, this viscosifying power is affected at higher temperatures and in the brine presence.

Furthermore, the surfactant polymer can down the interfacial tension between the water-based polymer solution (10.000 ppm polymer and $5.000 \mathrm{ppm} \mathrm{NaCl}$ ) and oil to $2.5256 \mathrm{nN} / \mathrm{m}$ at $60^{\circ} \mathrm{C}$.

The developed polyglycerol-based polymer materials reveal their high potential for enhancing oil recovery and related applications by tunning viscosifying and surfactant properties through the functionalization of the polyglycerol backbone. It is considered further EOR tests (rock-fluid displacement and mechanical, chemical, thermal, and biological degradation) to continue studying the viability of these lowcost polyglycerol-derived polymers.

\section{Data Availability}

This work is performed jointly to ECOPETROL S.A., the Colombian state Oil and Gas Company. Accordingly, we kindly request that the availability of data should be restricted due to commercial confidentiality.

\section{Conflicts of Interest}

The authors declare no competing financial interest.

\section{Acknowledgments}

This study was supported under the framework agreement 5222395 and subagreement 25 between the Universidad Industrial de Santander (UIS) and ECOPETROL. The Laboratorio de Química de Producción of ECOPETROL at the Instituto Colombiano del Petróleo (ICP) and María Carolina Ruíz are gratefully acknowledged.

\section{Supplementary Materials}

the supplementary file includes discussion related to the infrared spectroscopy analysis. (Supplementary Materials)

\section{References}

[1] J. J. Sheng, B. Leonhardt, and N. Azri, "Status of polymerflooding technology," Journal of Canadian Petroleum Technology, vol. 54, no. 2, pp. 116-126, 2015.

[2] X.'e. Li, Z. Xu, H. Yin, Y. Feng, and H. Quan, "Comparative studies on enhanced oil recovery: thermoviscosifying polymer versus polyacrylamide," Energy \& Fuels, vol. 31, no. 3, pp. 2479-2487, 2017.

[3] R. H. C. Garcia, G. A. M. Toro, R. J. Diaz et al., "Polymer flooding to improve volumetric sweep efficiency in waterflooding processes," CT\&F - Ciencia, Tecnología y Futuro, vol. 6, no. 3, pp. 71-90, 2016.

[4] D. A. Z. Wever, F. Picchioni, and A. A. Broekhuis, "Polymers for enhanced oil recovery: a paradigm for structure-property relationship in aqueous solution," Progress in Polymer Science, vol. 36, no. 11, pp. 1558-1628, 2011.

[5] M. Sveistrup, F. van Mastrigt, J. Norrman, F. Picchioni, and K. Paso, "Viability of biopolymers for enhanced oil recovery," Journal of Dispersion Science and Technology, vol. 37, no. 8, pp. 1160-1169, 2016.
[6] M. R. Monteiro, C. L. Kugelmeier, R. S. Pinheiro, M. O. Batalha, and A. da Silva César, "Glycerol from biodiesel production: technological paths for sustainability," Renewable and Sustainable Energy Reviews, vol. 88, pp. 109-122, 2018.

[7] 2017, R., Renewables 2017 Global Status Report, REN21 Secretariat, Paris, 2017.

[8] Co-operation, O f E and Development, OECD-FAO agricultural outlook 2018-2027, OECD Publishing, 2018.

[9] I. Ambat, V. Srivastava, and M. Sillanpää, "Recent advancement in biodiesel production methodologies using various feedstock: a review," Renewable and Sustainable Energy Reviews, vol. 90, pp. 356-369, 2018.

[10] X. Luo, X. Ge, S. Cui, and Y. Li, "Value-added processing of crude glycerol into chemicals and polymers," Bioresource Technology, vol. 215, pp. 144-154, 2016.

[11] D. Wilms, S.-E. Stiriba, and H. Frey, "Hyperbranched polyglycerols: from the controlled synthesis of biocompatible polyether polyols to multipurpose applications," Accounts of Chemical Research, vol. 43, no. 1, pp. 129-141, 2010.

[12] D. Steinhilber, S. Seiffert, J. A. Heyman, F. Paulus, D. A. Weitz, and R. Haag, "Hyperbranched polyglycerols on the nanometer and micrometer scale," Biomaterials, vol. 32, no. 5, pp. 13111316, 2011.

[13] S. Salehpour and M. A. Dubé, “Towards the sustainable production of higher-molecular-weight polyglycerol," Macromolecular Chemistry and Physics, vol. 212, no. 12, pp. 12841293, 2011.

[14] A. Sunder, R. Hanselmann, H. Frey, and R. Mülhaupt, "Controlled synthesis of hyperbranched polyglycerols by ringopening multibranching polymerization," Macromolecules, vol. 32, no. 13, pp. 4240-4246, 1999.

[15] R. Tokar, P. Kubisa, S. Penczek, and A. Dworak, "Cationic polymerization of glycidol: coexistence of the activated monomer and active chain end mechanism," Macromolecules, vol. 27, no. 2, pp. 320-322, 1994.

[16] D. Wilms, F. Wurm, J:. Nieberle, P. Böhm, U. Kemmer-Jonas, and H. Frey, "Hyperbranched polyglycerols with elevated molecular weights: a facile two-step synthesis protocol based on polyglycerol macroinitiators," Macromolecules, vol. 42, no. 9, pp. 3230-3236, 2009.

[17] G. Rokicki, P. Rakoczy, P. Parzuchowski, and M. Sobiecki, "Hyperbranched aliphatic polyethers obtained from environmentally benign monomer: glycerol carbonate," Green Chemistry, vol. 7, no. 7, pp. 529-539, 2005.

[18] A. Mohsenatabar Firozjaii and H. R. Saghafi, "Review on chemical enhanced oil recovery using polymer flooding: fundamentals, experimental and numerical simulation," Petroleum, vol. 6, no. 2, pp. 115-122, 2020.

[19] M. A. Ahmadi and S. R. Shadizadeh, "Induced effect of adding nano silica on adsorption of a natural surfactant onto sandstone rock: experimental and theoretical study," Journal of Petroleum Science and Engineering, vol. 112, pp. 239-247, 2013.

[20] M. A. Ahmadi, "Use of nanoparticles to improve the performance of sodium dodecyl sulfate flooding in a sandstone reservoir," The European Physical Journal Plus, vol. 131, no. 12, p. $435,2016$.

[21] C. Ardila-Suárez, D. Rojas-Avellaneda, and G. E. RamirezCaballero, "Effect of temperature and catalyst concentration on polyglycerol during synthesis," International Journal of Polymer Science, vol. 2015, Article ID 910249, 8 pages, 2015. 
[22] F. Wurm, U. Kemmer-Jonas, and H. Frey, "Hyperbranchedlinear-hyperbranched ABA-type block copolymers based on poly(ethylene oxide) and polyglycerol," Polymer International, vol. 58, no. 9, pp. 989-995, 2009.

[23] Y. Chen, Z. Shen, E. Barriau, H. Kautz, and H. Frey, "Synthesis of multiarm star poly(glycerol)-block-poly(2-hydroxyethyl methacrylate)," Biomacromolecules, vol. 7, no. 3, pp. 919926, 2006.

[24] A. Djukić-Vuković, D. Mladenović, J. Ivanović, J. Pejin, and L. Mojović, "Towards sustainability of lactic acid and polylactic acid polymers production," Renewable and Sustainable Energy Reviews, vol. 108, pp. 238-252, 2019.

[25] C. Gottschalk, F. Wolf, and H. Frey, "Multi-arm star poly(llactide) with hyperbranched polyglycerol core," Macromolecular Chemistry and Physics, vol. 208, no. 15, pp. 1657-1665, 2007.

[26] M. Adeli, H. Namazi, F. du et al., "Synthesis of multiarm star copolymers based on polyglycerol cores with polylactide arms and their application as nanocarriers," RSC Advances, vol. 5, no. 20, pp. 14958-14966, 2015.

[27] H. A. Wittcoff, B. G. Reuben, and J. S. Plotkin, Industrial organic chemicals, John Wiley \& Sons, 2012.

[28] D. Sun, Y. Yamada, S. Sato, and W. Ueda, "Glycerol as a potential renewable raw material for acrylic acid production," Green Chemistry, vol. 19, no. 14, pp. 3186-3213, 2017.

[29] G. M. Lari, G. Pastore, M. Haus et al., "Environmental and economical perspectives of a glycerol biorefinery," Energy \& Environmental Science, vol. 11, no. 5, pp. 1012-1029, 2018.

[30] B. S. Fernandes, J. Carlos Pinto, E. C. M. Cabral-Albuquerque, and R. L. Fialho, "Free-radical polymerization of urea, acrylic acid, and glycerol in aqueous solutions," Polymer Engineering \& Science, vol. 55, no. 6, pp. 1219-1229, 2015.

[31] Z. Shen, Y. Chen, E. Barriau, and H. Frey, "Multi-arm star polyglycerol-block-poly(tert-butyl acrylate) and the respective multi-arm poly(acrylic acid) stars," Macromolecular Chemistry and Physics, vol. 207, no. 1, pp. 57-64, 2006.

[32] F. Wiesbrock, R. Hoogenboom, and U. S. Schubert, "Microwave-assisted polymer synthesis: state-of-the-art and future perspectives," Macromolecular Rapid Communications, vol. 25, no. 20, pp. 1739-1764, 2004.

[33] C. Zhang, L. Liao, and S. (. S.). Gong, "Recent developments in microwave-assisted polymerization with a focus on ringopening polymerization," Green Chemistry, vol. 9, no. 4, pp. 303-314, 2007.

[34] K. Salimi, M. Topuzogullari, S. Dincer, H. M. Aydin, and E. Piskin, "Microwave-assisted green approach for graft copolymerization ofl-lactic acid onto starch," Journal of Applied Polymer Science, vol. 133, no. 6, 2016.

[35] E. Makhado, S. Pandey, P. N. Nomngongo, and J. Ramontja, "Fast microwave-assisted green synthesis of xanthan gum grafted acrylic acid for enhanced methylene blue dye removal from aqueous solution," Carbohydrate Polymers, vol. 176, pp. 315-326, 2017.

[36] L. C. Solano-Delgado, C. A. Bravo-Sanabria, C. Ardila-Suárez, and G. E. Ramírez-Caballero, "Stimuli-responsive hydrogels based on polyglycerol crosslinked with citric and fatty acids," International Journal of Polymer Science, vol. 2018, Article ID 3267361, 8 pages, 2018.

[37] M. Ghadamyari, S. Chaemchuen, K. Zhou et al., "One-step synthesis of stereo-pure 1,1 lactide from 1 -lactic acid," Catalysis Communications, vol. 114, pp. 33-36, 2018.
[38] S. Salehpour, C. J. Zuliani, and M. A. Dubé, "Synthesis of novel stimuli-responsive polyglycerol-based hydrogels," European Journal of Lipid Science and Technology, vol. 114, no. 1, pp. 92-99, 2012.

[39] H. Ying, G. He, L. Zhang, Q. Lei, Y. Guo, and W. Fang, "Hyperbranched polyglycerol/poly(acrylic acid) hydrogel for the efficient removal of methyl violet from aqueous solutions," Journal of Applied Polymer Science, vol. 133, no. 5, 2016.

[40] Y. Lin, A. Zhang, and L. Wang, "Synthesis and characterization of star-shaped poly(ethylene glycol)-block-poly(L-lactic acid) copolymers by melt polycondensation," Journal of Applied Polymer Science, vol. 124, no. 6, pp. 4496-4501, 2011.

[41] X. Wu, S. Li, F. Coumes, V. Darcos, J. Lai Kee Him, and P. Bron, "Modeling and self-assembly behavior of PEGPLA-PEG triblock copolymers in aqueous solution," Nanoscale, vol. 5, no. 19, pp. 9010-9017, 2013.

[42] M. L. Maminski, R. Szymański, P. Parzuchowski, A. Antczak, and K. Szymona, "Hyperbranched polyglycerols with bisphenol A core as glycerol-derived components of polyurethane wood adhesives," BioResources, vol. 7, no. 2, p. 12, 2012.

[43] M. Micutz, R. M. Lungu, V. Circu, M. Ilis, and T. Staicu, "Hydrogels obtained via $\gamma$-irradiation based on poly(acrylic acid) and its copolymers with 2-hydroxyethyl methacrylate," Applied Sciences, vol. 10, no. 14, p. 4960, 2020.

[44] S. Pásztor, B. Iván, and G. Kali, "Extreme difference of polarities in a single material: poly(acrylic acid)-based amphiphilic conetworks with polyisobutylene cross-linker," Journal of Polymer Science Part A: Polymer Chemistry, vol. 55, no. 11, pp. 1818-1821, 2017.

[45] E. Aliabadian, M. Kamkar, Z. Chen, and U. Sundararaj, "Prevention of network destruction of partially hydrolyzed polyacrylamide (HPAM): effects of salt, temperature, and fumed silica nanoparticles," Physics of Fluids, vol. 31, no. 1, article 013104, 2019.

[46] L. F. Lopes, B. M. O. Silveira, and R. B. Z. L. Moreno, Rheological Evaluation of HPAM fluids for EOR Applications, State University of Campinas International Journal of Engineering \& Technology IJET-IJENS, 2014.

[47] A. Zaitoun and B. Potie, "Limiting conditions for the use of hydrolyzed polyacrylamides in brines containing divalent ions," in SPE Oilfield and Geothermal Chemistry Symposium, Denver, Colorado, 1983.

[48] D. Levitt and G. A. Pope, "Selection and screening of polymers for enhanced-oil recovery," in In SPE symposium on improved oil recovery, Tulsa, Oklahoma, USA, 2008.

[49] H. Kato, F. Nakatsubo, K. Abe, and H. Yano, "Crosslinking via sulfur vulcanization of natural rubber and cellulose nanofibers incorporating unsaturated fatty acids," RSC Advances, vol. 5, no. 38, pp. 29814-29819, 2015.

[50] K. A. Elraies, I. M. Tan, M. Awang, and I. Saaid, "The synthesis and performance of sodium methyl ester sulfonate for enhanced oil recovery," Petroleum Science and Technology, vol. 28, no. 17, pp. 1799-1806, 2010. 